\title{
El juego de las apariencias Las connotaciones del vestido a fines del siglo XIX en la ciudad de México
}

\section{The game of appearances \\ Clothing connotations by the end of the 19th century in Mexico City}

\author{
FLORENCIA GUTIÉRREZ \\ Instituto Superior de Estudios Sociales (UNT-CONICET) \\ Dra. en Historia, El Colegio de México \\ San Lorenzo 429, Tucumán, Argentina \\ florenciagutierrezb@yahoo.com
}

\begin{abstract}
RESUMEN Las elites porfirianas de fines del siglo XIX intentaron transformar determinados hábitos y conductas de las clases populares de la ciudad de México por considerar que contravenían las exigencias de la civilización y el progreso y retrasaban la consolidación de la urbe capitalina como referente de la modernidad. En este contexto, el deseo por modificar los atuendos y costumbres higiénicas de los sectores populares constituyó una preocupación destacada de la administración de Porfirio Díaz. El objetivo de este artículo es analizar las connotaciones que la indumentaria tuvo para la dirigencia mexicana y estudiar las respuestas sociales frente a las coerciones destinadas a modificar la forma de vestir y asearse de ciertos segmentos de la población capitalina.
\end{abstract}

Palabras clave vestido, higiene, clases populares

ABSTRACT Late 19th-century elites tried to change certain habits and behaviour of Mexico City's popular classes, which were considered to run

Artigo recebido em: setembro/2008. 
counter to the demands of civilization and progress thus delaying the consolidation of the capital city's urbanization as a referent of modernity. In this context, the wish to modify clothes and hygiene habits of popular sectors became a paramount concern for Porfirio Diaz's administration. The aim of this article is to analyze the connotations clothing had for Mexico's leading sectors and to study the social response to the coercion destined to alter dressing and sanitation habits in a given group of capital-city dwellers.

Keywords clothing, hygiene, popular classes

\section{Introducción}

En el afán por situar a México en el concierto de las naciones modernas, las elites porfirianas intentaron transformar hábitos y conductas de las clases populares urbanas. En este contexto, a fines del siglo XIX en la ciudad de México confluyeron diversos proyectos moralizadores y disciplinadores destinados a erradicar comportamientos que contravenían las exigencias de la llamada civilización y el anhelado progreso․ La lucha contra la embriaguez y el San Lunes, la preocupación por adecuar la vestimenta y la higiene de los trabajadores a las normas de la modernidad, así como la estricta reglamentación de pulquerías, figones y cantinas pretendían insuflar en los sectores populares una ética laboral sustentada en la disciplina y la obediencia; una conducta pública afirmada en las sanas y moderadas diversiones y un comportamiento privado atento al respeto por la familia y la interiorización de hábitos de ahorro y limpieza².

Las elites políticas intentaron promover el uso del pantalón y ciertas prácticas de aseo, tanto en la ropa como en el cuerpo de las clases populares urbanas. Por ejemplo, procuraron desterrar el calzón de manta que permitía "circular el aire frío con entera libertad" y dejaba ver "el bronce viviente que no ha purificado el agua"3 y pusieron en marcha campañas destinadas a uniformar al contingente laboral, a fin de adecuar la apariencia de voceadores, cargadores y billeteros a los parámetros de orden y limpieza que exigía una urbe cosmopolita. La preocupación por el vestido, cruzada por prejuicios y valoraciones morales, desempeñó un papel catalogador proclive a convalidar la pertenencia a un determinando sector social y tendiente a

1 Las elites políticas mexicanas, al igual que sus pares latinoamericanas, se apropiaron de la metáfora civilizaciónprogreso, la cual marcó la construcción del Estado-nación a lo largo del siglo XIX. Ese binomio se constituyó en la medida de modernidad de las nuevas naciones, ya que a la vez que suponía la idea de perfectibilidad y evolución, indicaba un estado observable y deseable en las sociedades.

2 Diversas miradas y perspectivas de análisis sobre la experiencia de la modernidad y la persistencia de la tradición en la ciudad de México al cambio de siglo en AGOSTONI, Claudia y Elisa SPECKMAN. Modernidad, tradición y alteridad. La ciudad de México en el cambio del siglo (XIX y XX). México: Universidad Nacional Autónoma de México, 2001.

3 RUIZ, Arturo. El vestido ante la higiene. México: Tipografía artística, 1904, p.26. 
prejuzgar conductas privadas y comportamientos públicos. Mientras que una apariencia pulcra se convirtió en símbolo de moralidad y garantía del orden social, cuerpos y vestidos desaseados se impusieron en el imaginario finisecular como amenazas latentes contra la denominada paz porfiriana.

En esta tónica de preocupaciones, a lo largo de este artículo el vestido es aprehendido como un "hecho social global"4, como "un medio de evocación pintoresca de los excesos de las clases superiores y de la cotidianeidad popular"5 y un observatorio privilegiado para reflexionar acerca de las costumbres, las imposiciones y resistencias culturales, los prejuicios y las jerarquías sociales. Entendemos que el estudio de las connotaciones del vestido posibilita comprender, desde una singular perspectiva de análisis, cómo se vincularon los ideales y proyectos modernizadores del poder político porfiriano con los hábitos de las clases populares urbanas; ${ }^{6}$ en síntesis, permite acercarnos a ese proceso siempre "sensible e intelectual de apropiación del mundo". ${ }^{7}$

\section{EI vestido: entre ilustrados y liberales}

Desde fines del siglo XVIII en la Nueva España la impronta de la llustración conllevó a la proliferación de reglamentos, decretos y reales cédulas destinados a lograr que los sectores populares interiorizaran un código de conducta basado en la moral y las "buenas costumbres". ${ }^{8}$ El propósito era erradicar, o al menos reformar, lo que los ilustrados consideraban como relajadas y viciadas conductas populares y, por ende, desterrar de la ciudad

4 ROCHE, Daniel. «La cultura material a través de la historia de la indumentaria», en DE GORTARI, Hira y Guillermo ZERMEÑNO. Historiografía francesa. Corrientes temáticas y metodologías recientes. México: Centro Francés de Estudios Mexicanos y Centroamericanos, Centro de Investigaciones y Estudios Superiores en Antropología Social, Instituto de Investigaciones Históricas Universidad Nacional Autónoma de México, Instituto Mora, Universidad Iberoamericana, 1996, p.81.

5 ROCHE, Daniel. La culture des apparences: une historie du vêtement XVII e XVIII e siècle. Citado en GONZALBO AIZPURU, Pilar. Introducción a la historia de la vida cotidiana. México: El Colegio de México, 2006, p.227.

6 Las hojas sueltas y cuadernillos de la editorial de Antonio Vanegas Arroyo, destinados al gran público, coadyuvan a complejizar la dicotomía existente entre prácticas populares e ideales modernizadores porfirianos. Elisa Speckman señala que "los principios, los modelos y las pautas de conducta [... ], plasmados en los impresos, fueron formulados por y eran característicos de la clase privilegiada y de los sectores medios, pero resultaban lejanos a las prácticas e incluso a las posibilidades de los grupos populares [... Se enaltecían el matrimonio y las prácticas de higiene, mientras que el amasiato era el vínculo más usual, y el lavado del cuerpo y las ropas eran poco frecuentes. SPECKMAN, Elisa. Pautas de conducta y códigos de valores en los impresos de Vanegas y Arroyo, en OLEA FRANCO, Rafael. Literatura mexicana de fin de siglo. México: El Colegio de México, 2001, p.448.

7 ROCHE, Daniel. La culture des apparences: une historie du vêtement XVII e XVIII e siècle. París: Fayard, 1996, pp. 80-81. Con el estudio del vestido “c'est donc un peu l’histoire des logiques de médiation que l’on voudrait éclairer. Pour cela, passer des modalités de consommation à l'évocation du système parisien de fabrication, de distribution permet de franchir une étape, interrogeant fabricants, vendeurs, clientèles. Enfin, tenter de voir entre le réel et l'imaginaire le rôle social des apparences, de l'économie stationnaire à celle de la consommation, suppose qu'on interroge d'autres modes de présentation et d'autres logiques révélatrices de l'existence sociale”. ROCHE, Daniel. La culture des apparences: une historie du vêtement XVII e XVIII e siècle, p.27.

8 Es preciso señalar que en el siglo XVIII la nueva moral burguesa entendía que "los pobres se habían forjado su triste destino por su ociosidad, su inmoralidad, su falta de decencia. Reprimirlos con paternal severidad, no constituía un acto de crueldad, sino por el contrario era una forma de ayudarlos a abandonar sus relajadas costumbres, de encarrilarlos por el buen camino, en resumen, de educarlos”. VIQUEIRAALBÁN, Juan Pedro. ¿Relajados o reprimidos? Diversiones públicas y vida social en la ciudad de México durante el Siglo de las Luces. México: Fondo de Cultura Económica, 1987, p.269. 
ciertos espacios de diversión pública discordantes con la emergente modernidad del Siglo de las Luces, que encontraba su correlato en la moderación de los comportamientos sociales. ${ }^{9}$

En este contexto de preocupaciones, las autoridades virreinales reprimieron ámbitos de sociabilidad -como las corridas de toros- y sometieron a una estricta reglamentación determinados espacios y espectáculos populares -como el teatro y el carnaval- por considerar que poco tenían que ver con el ideal de la eutropelia, es decir, "con la prudencia moral que nos enseña a dar treguas a nuestras fatigas [... ] mediante una moderada diversión que restableciendo con la alegría la natural laxitud de nuestro espíritu, nos vuelva más alegres y entonados al trabajo". ${ }^{10}$ Asimismo, "los ilustrados arengaron en sus escritos a los artesanos para que mostraran más entusiasmo por el trabajo y no perdieran su tiempo y su dinero en merendonas ni embriagueces" que llevaban a convertir el lunes en día de fiesta. ${ }^{11}$

La vestimenta y el aseo de las clases populares también fue una preocupación del poder político colonial que, entre otras medidas, reglamentó para los indígenas el uso de la casaca o capa para asistir a las funciones públicas. Asimismo, en 1790 la elite ilustrada llevó adelante una campaña para combatir entre los trabajadores de las fábricas de cigarros y los empleados del Estado la "desnudez de la plebe". La indecencia de la vestimenta reflejada en los calzoncillos y la manta que envolvía el cuerpo de los trabajadores era considerada como un exponente "vehementísimo de ociosidad o malas costumbres". Con el fin de ampliar el alcance social de esta medida, el virrey Branciforte expidió una reglamentación para "que en las juntas de gremios y en las de cofradías o hermandades que hay en el reino, no se admita persona alguna que no vaya decentemente vestida conforme a sus facultades [...] que ni en las procesiones, ni en las calles pordonde pasen éstas, ni en los paseos públicos [...] pueda haber persona alguna que no tenga cubiertas las carnes con decencia según su clase". ${ }^{12}$ Este afán moralizador de los ilustrados, encarnado en la preocupación por las apariencias, pretendía interiorizar en amplios sectores de la población un código de decencia acorde con los requisitos que la "civilidad" exigía.

9 Destacamos el trabajo de J uan Pedro Viqueira Albán, quien analiza el discurso moralizador de los ilustrados y los mecanismos implementados en la Nueva España contra el "relajamiento" de las costumbres populares. VIQUEIRA ALBÁN, J uan Pedro. ¿Relajados o reprimidos? Diversiones públicas y vida social en la ciudad de México durante el Siglo de las Luces. Para el caso de Guatemala remitimos al trabajo de Tania Sagastume Paiz. De la ilustración al liberalismo. Los discursos sobre los gremios, el trabajo y la vagancia en Guatemala, en LIDA, Clara y Sonia PÉREZ TOELDO. Trabajo, ocio y coacción. Trabajadores urbanos en México y Guatemala en el siglo XIX. México: Universidad Autónoma Metropolitana, Miguel Ángel Porrúa, 2001, pp.19-65.

10 FERNÁNDEZ DE LIZARDI, citado en VIQUEIRA ALBÁN, J uan Pedro. ¿Relajados o reprimidos? Diversiones públic as y vida social en la ciudad de México durante el Siglo de las Luces, p.267.

11 VIQUEIRA ALBÁN, J uan Pedro. ¿Relajados o reprimidos? Diversiones públicas y vida social en la ciudad de México durante el Siglo de las Luces, p.273.

12 LEMPÉRIÈRE, Annick. República y publicidad a finales del Antiguo Régimen (Nueva España), en GUERRA, François Xavier y Annick LEMPÉRIĖRE. Los espacios públicos en Iberoamérica. Ambigüedades y problemas. Siglos XVII y XIX. México: Centro Francés de Estudios Mexicanos, Fondo de Cultura Económica, 1998, pp.65-66. 
Durante el porfiriato el vestuario de las clases populares retomó la impronta ilustrada, que asociaba la indumentaria con la decencia, pero profundizó ciertas connotaciones al vincular con una fuerza inusitada la moralidad y limpieza en el vestir con la conservación del orden social y la preservación de la salud de la sociedad en su conjunto. Para las elites políticas a la vez que el calzón de manta, los huaraches y el zarape impugnaban la marcha de los proyectos modernizadores, cuestionando la inserción de México en el mundo cosmopolita, constituían el síntoma más evidente de la falta de moral de sus portadores y, por ende, revelaban los peligros y amenazas que se cernían sobre la promocionada paz porfiriana.

A principios del siglo XX, el español J ulio Sesto sentenciaba que el uso del calzón entre los indígenas de la ciudad y la "carencia de agua" que evidenciaban las ropas de "ciertas clases obreras de mayores recursos que el indio" terminaban equiparando a estos sectores con "turbas abigarradas [...] que salpican la cultura mexicana, destacándose en medio de una calle asfaltada, recortando su silueta contra una fachada suntuosa, mezclándose, de manera que hiere la retina, con los caballeros de gabán inglés y las damas de vestido directorio y constituyendo, en una palabra, la nota discordante". ${ }^{13}$ Esta cita condensa el contraste que existía entre la preocupación por dotar a la capital de la República con los símbolos del progreso y los denodados esfuerzos de las elites por adoptar la moda, los deportes y las diversiones de las grandes capitales europeas con la imagen que proyectaban, principalmente en lo tocante a su vestuario e higiene, las clases populares urbanas ${ }^{14}$.

La falta de pulcritud en el vestido no sólo ponía en entredicho los logros y adelantos del país, sino que constituía una grave amenaza para la conservación de la paz porfiriana y la salud de la ciudadanía urbana. Podemos decir que a fines del siglo XIX, la indumentaria de los sectores populares constituyó una preocupación política, en tanto siguió considerándose un parámetro que servía para medir la civilización y el progreso citadino, pero cada vez con mayor fuerza sus implicaciones se vincularon con la moralidad, la higiene y el orden social. Retomando el estudio de la limpieza corporal de Georges Vigarello, podemos decir que en el México decimonónico "finalmente se va imponiendo con insistencia desconocida hasta ese momento

13 SESTO, Julio. A través de América. El México de Porfirio Díaz (hombres y cosas). Estudios sobre el desenvolvimiento general de la República mexicana. Observaciones hechas en el terreno oficial y en el particular. Valencia: F. Sempere y Compañía, Editores, 1910, p.232.

14 Remitimos a BEEZLEY, William. El estilo porfiriano: deportes y diversiones de fin de siglo. Revista Historia Mexicana, ciudad de México, vol. XXXII, n² 2, pp.265-284, octubre-diciembre de 1983 y BEEZLEY, William; Cherly ENGLISH MARTIN y William FRENCH (editores). Rituals of Rule, Rituals of Resistance. Public Celebrations and Popular Culture in Mexic o. Wilmington: Scholary Resources, 1994. 
una asociación: la limpieza del pobre se convierte en garantía de moralidad que, a su vez, es garantía de orden". ${ }^{15}$

\section{La higiene como garantía de la paz porfiriana}

Se notan en el pueblo de México [... d dos padecimientos idiosincráticos que desagradan: la paupérrima y sucia indumentaria y la extremosa inclinación a la embriaguez [...]

El indio anda en calzoncillos por las ciudades [... ] y siquiera esos calzoncillos fueran limpios y ... sin ventanas... [El calzón blanco] al ceñirse en sus ondulaciones flexibles a las flacideces masculinas, denuncia relieves 0 muestra por sus agujeros impudicias de cafrería.

Quienes así se visten [... ] perciben un salario de un peso al día, en las capitales; de este peso injieren en alcohol o pulque la mitad diariamente, y el resto se lo beben el sábado de una sentada. ${ }^{16}$

Para las elites porfirianas la falta de moral entre las clases populares explicaba la continuidad del calzón de manta, así como la falta de hábitos higiénicos y el no menos preocupante problema del alcoholismo ${ }^{17}$. Estos tópicos, fuertemente interrelacionados, repercutían negativamente en la salud y la moral del resto de los ciudadanos y restaban crédito a la imagen de ciudad moderna y cosmopolita que las autoridades políticas deseaban exportar por el mundo.

La falta de limpieza que la ropa dejaba traslucir y la carencia de costumbres y preceptos higiénicos corporales eran considerados un síntoma de la ignorancia e inmoralidad de las clases populares, que afectaba no sólo la salud de su portador, sino de la población en general. Por ello, para evitar la difusión de enfermedades y epidemias era necesario transformar los hábitos de aseo de estos sectores. "Las libertades que la ley fundamental garantiza al ciudadano tienen un límite al redundar en perjuicio de terceros, y perjuicio y muy grande ocasiona a la higiene pública el desaseo de nuestro pueblo, fuente y origen [...] de que las enfermedades se recrudezcan, de que se conviertan en epidemias". ${ }^{18}$

Por lo tanto, "la teoría y la práctica de la higiene", estrechamente vinculada al juego de las apariencias, no sólo constituyó una imperiosa necesidad para la consolidación de una moderna cultura urbana, sino

15 VIGARELLO, Georges. Lo limpio y lo sucio. La higiene del cuerpo desde la Edad Media. Barcelona: Altaza, 1997, p.240.

16 SESTO, Julio. A través de América. El México de Porfirio Díaz (hombres y cosas). Estudios sobre el desenvolvimiento general de la República mexicana. Observaciones hechas en el terreno oficial y en el particular, p.232.

17 ¿Es posible que el obrero, que lleva los pantalones rotos, la camisa sucia, los dedos de los pies fuera de los zapatos, el cabello saliéndosele por los agujeros del sombrero, en lugar de ir poco a poco reponiendo esas prendas de su vestido, se meta en la pulquería y esté en continuo estado de embriaguez durante 48 horas, todas las semanas?, El Socialista, 18 de marzo de 1888, reproducido de La Paz Pública.

18 El Nacional, 10 de junio de 1888. 
que "se convirtió en una herramienta indispensable mediante la cual se quería modificar o eliminar hábitos, prácticas y costumbres consideradas por los médicos como peligrosas para la salud de la colectividad". ${ }^{19}$ Los afanes higienistas encontraron en la población múltiples obstáculos para su concreción, uno de los principales problemas radicaba en las arraigadas usanzas de las clases populares, en sus prejuicios y falsas concepciones acerca de lo que era higiénico. En los sectores más pobres de la ciudad la falta de hábitos de aseo corporal, cruzada de prejuicios en torno a las dañinas consecuencias que podrían sufrir en caso de bañarse todos los días, constituyó uno de los más serios problemas para lograr la anhelada consolidación de ciudadanos limpios y sanos. El caso de los trabajadores de la fábrica de tabaco El Buen Tono constituye un ilustrativo ejemplo de la confrontación sociocultural entre las prácticas y concepciones populares y los preceptos higiénicos imperantes a fines del siglo XIX.

Ayer en la mañana, los cargadores de maniobras de la fábrica de cigarros "El Buen Tono" no entraron a trabajar [...]

Se desprende de sus informes que el enojo provenía de que los obligaban a cortarse el pelo y lavarse todos los días, con lo cual podían contraer enfermedades, y además los hacían maniobrar los domingos, sin remuneración.

[... f fue uno de nuestros compañeros a la citada fábrica y allí le informó el Sr. D. Baldomero Prida que, en efecto, antes que empezaran sus labores que son, entre otras, las de verificar revolturas de tabaco, cuya limpieza y aseo son indispensables, debían lavarse todos los días, los pies, cara, cabeza y manos; pero que esta operación lejos de ser un peligro para la salud, implicaba una de las principales reglas de higiene. ${ }^{20}$

En este contexto, en 1892 la preocupación gubernamental por la higiene de los sectores populares se materializó en el proyecto de impresión de un periódico que, denominado La Higiene Popular, estaría subvencionado por las Secretarías de J usticia y de Fomento. Sus promotores, los médicos Secundino Sosa y Samuel Morales Pereira, señalaron que el objetivo del periódico era la "propaganda y vulgarización de las nociones y preceptos de la higiene [...] para hacerlos cumplir por persuasión suave y por convencimiento profundo". El fundamento de los ideólogos del proyecto evidencia la densa trama que en los tiempos porfirianos vinculaba la higiene con la moral y la modernización.

19 AGOSTONI, Claudia. Salud pública y control social en la Ciudad de México a fines del siglo diecinueve. Revista Historia y grafía, ciudad de México, n 17, pp.73-97, 2001 y AGOSTONI, Claudia. Monuments of Progress. Modernization and Public Health in Mexico City, 1876-1910. Canadá: University of Calgary Press, University Press of Colorado, Instituto de Investigaciones Históricas, Universidad Nacional Autónoma de México, 2003. Epecialmente remitimos a los capítulos 2 y 3.

20 El Noticioso, 22 de mayo de 1895. 
Ya tenemos Consejo de Salubridad y Código Sanitario, o lo que es lo mismo ya tiene la salud pública autoridad y ley; pero falta el pueblo para esa ley y para esa autoridad. Porque es inconcuso que en vano existen la prescripción y el encargado de hacerla observar, si el obligado al cumplimiento no sabe cuál es su obligación, ni cómo ha de cumplirla.[...]

Tras largo y doloroso bregar hemos conseguido leyes, sosiego, ferrocarriles y bancos: ahora necesitamos tener pueblo, pero no el pueblo harapiento y enfermizo, sino el pueblo viril y sano que sabe trabajar y ahorrar, vestir y comer, educar a la familia y tener aspiraciones para el porvenir. ${ }^{21}$

Según los impulsores de esta empresa editorial, el gobierno había brindado el sustento legal y el marco institucional que la salubridad pública necesitaba, lo que seguía era inculcar al pueblo la necesidad, los hábitos y los valores de la higiene y la salud. En este sentido, el diario se convertiría en una herramienta para la divulgación de estos principios y preceptos, complemento ideal de la obra educativa brindada en las escuelas. Para los médico-editores, el impacto social y los resultados que de la divulgación de la higiene se podían obtener eran equiparables con los adelantos que, durante la paz porfiriana, se habían alcanzado en materia de transporte, de finanzas o de legislación. De esta forma, la propagación de la higiene pública se convertía en un reto para hacer de la anhelada modernidad una realidad.

No menos trascendente era la concepción que argumentaba que debajo de una pobre, sucia y descuidada indumentaria se encontraban latentes dudosos y amenazantes comportamientos. En el caso de las clases populares urbanas, para las elites porfirianas la falta de higiene personal estaba estrechamente asociada con el problema del alcoholismo. El obrero que se dejaba "dominar por el vicio" - que gastaba la raya el sábado por la noche en los figones y el lunes no iba a trabajar-, se acostumbraba a la suciedad y a la miseria, vestía harapos, llevaba el calzado roto y el cabello hirsuto. En consecuencia, la embriaguez repercutía en todos los ámbitos de la vida del trabajador y alcanzaba a la sociedad: "el obrero que llega ebrio a su casa, que golpea su esposa y la tiene hambrienta, la obliga a prostituirse; el obrero que abandona a sus hijos, que no los envía a la escuela, que les da mal ejemplo, que no los alimenta, ni viste [... ] en vez de entregar a la sociedad hombres útiles, le arroja con cinismo perverso [sujetos] cuyo porvenir es la cárcel y muchas veces el patíbulo". ${ }^{22}$

Como señalamos, un escaso aseo personal delataba falta de moralidad y frente a esa carencia de principios la vinculación con ciertos vicios, como el alcoholismo, parecía obligada; en esta cadena de suposiciones y prejuicios el destino final de estos sujetos no podía ser otro que la delincuencia. En

21 Colección Porfirio Díaz, leg. 17, doc. 008215.

22 La Convención Radical Obrera, 6 de septiembre de 1891. 
la tabema el obrero perdía "la reputación, la moral, tal vez la tranquilidad de conciencia, y acaso la felicidad, [en la taberna podía verse] envuelto en una disputa causada por los humos del licor y acaso [cometer] un crimen o se[r] cómplice en él". ${ }^{23}$

En el caso de la vestimenta de las obreras mexicanas de fines del siglo XIX, el jurista y sociólogo J ulio Guerrero afirmó que acostumbraban a abrigarse con rebozos, vestían enaguas y sacos de percal, gustaban de adornarse con anillos de cobre y ebonita y acudían a sus trabajos peinadas con dos trenzas que unían por la espalda. ${ }^{24}$ En una interesante nota a pie de página, Guerrero retoma la descripción elaborada porJ osé Tomás de Cuéllaracerca del rebozo y sus usos, en ella el autor define esta prenda como:

Un chall [sic] escurridizo y cuya docilidad confianzuda la da el aspecto de usado desde antes de venderse. Debajo del rebozo se oculta la cabeza desgreñada, la camisa de semanas, la falta de abrigo para el cuello, la del corsé, la del corpiño y la de las mangas [... ] si llueve la propietaria se cubre la cabeza no para no mojarse, sino para aprovechar el agua filtrada; si hace frío el rebozo tapa la nariz, no para abrigarse, sino para hacerse la ilusión de que se defiende del frío, respirando su propio aliento $[\ldots]$ si se roba algo se esconde debajo del rebozo $[\ldots] .25$

Bajo una mirada signada por el clasismo, Cuéllar describe el rebozo como una prenda de dudosos, variados y antihigiénicos usos. Esta especie de chal se asociaba con un conjunto de prácticas y hábitos que, no exentos de prejuicios, permitían que la mujer encubriera con él la falta de hábitos higiénicos, la carencia de un vestuario limpio y adecuado y, en el peor de los casos, pudiera ocultar hasta lo robado.

Resulta interesante destacar la carga valorativa que envolvía a esta prenda cuya descripción variaba significativamente según la condición social de su portadora. Decimos esto porque, en algunos casos, el rebozo podía convertirse en una prenda de "exquisita elegancia [... ] que sirve de atavío a la belleza y a la juventud". Tal era el caso de las jovencitas de las colonias de la capital y de los pueblos, quienes usaban rebozos de seda de múltiples colores, los cuales "cruzan como banda sobre el pecho, ciñendo la cintura y dejando caer las puntas sobre la espalda". Paradójicamente, mientras que a algunas mujeres el rebozo les permitía lucir "toda la elegancia de su talle y cabeza", ${ }^{26}$ en otras, el rebozo servía para ocultar la cabeza desgreñada, la falta de ropa limpia y adecuada y podía llegar, incluso, a

23 El Socialista, 17 de enero de 1875.

24 GUERRERO, J ulio. La génesis del crimen en México. México: Consejo Nacional para la Cultura y las Artes, 1996, p.136.

25 GUERRERO, J ulio. La génesis del crimen en México, p.136. J osé Tomás de Cuéllar (1830-1894) fue un renombrado periodista y novelista mexicano. Entre sus novelas se destacan: Baile y cochino, Ensalada de pollos y Estampas del siglo XIX. Como periodista fundó el diario La llustración potosina y colaboró en los periódicos El Siglo XIX y La llustración mexicana.

26 GUERRERO, J ulio. La génesis del crimen en México, pp.136-137. 
encubrir el producto del latrocinio. La indeterminación en lo referente al uso y a los atributos de la prenda se explica atendiendo a las cuestiones de clase que subyacen en el discurso de Cuéllar; la prenda no se define por sí misma, por el contrario, es su portadora quien imprime y determina su carácter, su utilidad, sus virtudes o defectos.

También merece destacarse que, en algunos casos, la indumentaria de las clases populares fue la excusa para excluir de determinados ámbitos a quienes no vestían según los códigos y pautas consideradas como deseables. Por ejemplo, en 1895 un grupo de indígenas del Valle de México presentaron a las autoridades del Ayuntamiento capitalino un escrito denunciando que en razón de su "miserable traza" los policías les impedían el acceso a determinados lugares públicos o los echaban de ellos, "para que no avergoncemos a los ricos, a sus queridas, a sus lacayos y a sus directores de conciencia". La petición fue redactada en los siguientes términos:

Tratamos, señor, de que vuestra Ilustrada Honorabilidad, se digne a fijar su atención en un bando de policía, donde se hace patente la superioridad real 0 afectada que se tiene con respecto a nosotros. El pordiosero yankee, el clérigo español, la comparsa de leprosos que nos vienen de Italia, los vagos y leprosos de profesión [... ] todos se disputan la libertad de mezclarse con el público transitando cómodamente por las calles de la ciudad y teniendo libre acceso a las reuniones $[\ldots]$

Por lo expuesto, y en atención a que la miserable traza de los indios no es un efecto de sus vicios, sino del orgullo y la vanidad de la casta que los oprime [... ] A V. E. suplicamos se digne declarar insubsistente el bando que prohíbe que los indígenas pobres transiten por determinados centros de la ciudad, tomen asiento en determinados sitios de recreo, y puedan, pagando como todos, ocupar un palco en el teatro de la ópera o un reclinatorio en los templos llamados aristocráticos. ${ }^{27}$

En este caso "la miserable traza de los indios" era el estigma de una situación que sobrepasaba, en mucho, las cuestiones vinculadas con el vestido. En el juego de las apariencias, la indumentaria era una expresión de la discriminación social y de las diferencias de clase, un motivo para prejuzgar la moral y dignidad de su portador, una excusa para calificar, marginar y en ocasiones excluir a quienes - por su condición social- se les pretendía segregar de determinados espacios públicos.

En la petición elevada a las autoridades reconocemos la manifestación de un discurso con tintes nacionalistas y anticlericales, que estigmatizaba de igual forma a los ricos, a los clérigos y a los extranjeros. El repudio hacia esos sectores, así como la intención de modificar las bases del imaginario social construido alrededor de la figura del indígena, tradicionalmente 
identificado con los vicios y la inmoralidad, resulta evidente. De igual forma, es manifiesto el deseo de denunciar las condiciones de desigualdad que primaban en las relaciones sociales y la responsabilidad de quienes anteponiendo su "orgullo y vanidad" oprimían a los indios. Por ello, los más de mil firmantes acusaron de su "miserable" apariencia a sus opresores y exigieron poder transitar libremente por las calles de la ciudad y asistir a los espectáculos públicos.

Recapitulando, podemos decir que para las elites porfirianas la descuidada vestimenta y los escasos hábitos de higiene delataban la ignorancia y escasa moralidad de las clases populares urbanas. Aquellos cuerpos, asociados con la enfermedad, el alcoholismo y la delincuencia, ponían en peligro la estabilidad y continuidad de la paz porfiriana y atentaban contra la salud de la sociedad en su conjunto. Según esta concepción, la propagación de una cultura higiénica no sólo alcanzaría a transformar hábitos y costumbres de limpieza, en beneficio de la colectividad, sino que formaría parte de una campaña moralizadora que terminaría disciplinando cuerpos y conductas. En síntesis, la limpieza y pulcritud de la piel y la ropa representaban, a los ojos de las elites, una tranquilizadora imagen portadora de morales y aceptables comportamientos, sustento imprescindible del progreso y orden porfiriano.

\section{La vestimenta de las clases trabajadoras: imperativos externos y coacciones internas}

Inserto en este contexto de preocupaciones, en el que el atuendo de las clases populares constituyó uno de los parámetros para medir la civilidad y la modernización urbana, nos interesa rescatar las particularidades y connotaciones que el tema del vestido alcanzó en el universo artesanal mutualista y entre los trabajadores ambulantes, dos segmentos destacados del mundo laboral de la ciudad de México a fines del siglo XIX28.

En lo que respecta al supuesto de la benéfica influencia del mutualismo en la clase trabajadora, es pertinente destacar la reseña elaborada por el periodista y líder artesanal J osé María González y González, en ocasión de la fundación de una sociedad mutualista en el pueblo de Santa Anita. Allí, y ante la numerosa presencia de trabajadores indígenas, el dirigente argumentó

28 A fines del siglo XIX el asociacionismo mutualista se subordinó a los mandatos de la política porfirista, actuando en estrecha concordancia con los lineamientos oficialistas. En efecto, la sujeción de la confederación de trabajadores más destacada de la época, el segundo Congreso Obrero, y la actuación de La Convención Radical Obrera, club político alineado al poder público, fueron instituciones decisivas para lograr la asimilación política de los artesanos y obreros mutualistas y coadyuvar a la legitimidad del régimen de Díaz. Un análisis de la relación entre el poder porfiriano y el mutualismo en GUTIÉRREZ, María Florencia. El mundo del trabajo y el poder político. Integración, consenso y resistencia en la ciudad de México a fines del siglo XIX. México: El Colegio de México, 2006 (Historia, tesis de doctorado). Asimismo, para conocer el mundo ambulante de la ciudad de México remitimos a BARBOSA CRUZ, Roger Mario. El trabajo en la calle. Subsistencia y negociación política en la ciudad de México a comienzos del siglo XX. México: El Colegio de México, 2005 (Historia, tesis de doctorado). 
que "ya la blusa de lino o de dril, perfectamente limpia, ha sustituido a la legendaria cotona y al indispensable sarapito embrocado al cuello o echado al hombro izquierdo, lo mismo que el pantalón ha desterrado al ancho calzón de manta, y el calzado al típico huarache". ${ }^{29}$ Asimismo, señalaba que

Otra lucha ha sido necesario sostener contra la costumbre inveterada de I[as] indígenas en el vestido. Acostumbran a enredarse de la cintura para abajo un trozo de lienzo de lana que apenas les permite tener algún movimiento en las piernas [... ] pues bien esa costumbre ha sido vencida por la enagua blanca y la de encima, lo mismo que por el saco que cubre hasta abajo del talle y por la mascada alrededor del cuello [... L La civilización las va transformando y creando necesidades que las obliga a ser consumidoras y a tener as piraciones..$^{30}$

La transformación del vestuario - aunada a otros comportamientos- fue considerada como un indicador de la positiva injerencia que para los trabajadores aparejaba la integración en las sociedades mutualistas. La clase gobernante interpretó al mutualismo como uno de los ámbitos de sociabilidad que constituía "un elemento de orden y progreso para la nación y de auxilio eficaz y moralización para los obreros que la forman". ${ }^{31}$ Este tipo de asociacionismo, sujeto a los mandatos porfirianos, se convirtió en uno de los instrumentos civilizadores por excelencia.

El obrero que se asocia comienza por dignificarse [... ] mejora su traje, se peina, se asea, usa reloj, no bebe, aunque en la calle le insisten, porque tiene la noble aspiración de parecer bien en la junta [... ] ocupa la tribuna con desembarazo, le pierde miedo al público que va a escucharlo, y como desea que su discurso sea aplaudido, se empeña en hablar correctamente [... ] para esto tiene que leer, que buscar un lenguaje adornado de galas oratorias, tiene en fin, que civilizarse, y sin otro maestro que la necesidad, aprende de hombre lo que no aprendió de niño en la escuela. ${ }^{32}$

La condena dirigida a ciertas formas de vestir, hablar o asearse formó parte de un proceso "civilizador" que muchas veces implicó una transformación de los comportamientos y las conductas de los individuos, no únicamente sustentada en la coacción, sino también en el consenso ${ }^{33}$.

29 La Convención Radical Obrera, 8 de julio de 1898, en VILLALOBOS CALDERÓN, Liborio (comp.) La Convención Radical Obrera. La Antología. México: Centro de Estudios Históricos del Movimiento Obrero Mexicano, 1978, p.65.

30 La Convención Radical Obrera, 1 de enero de 1888.

31 La Convención Radical, 22 de mayo de 1887, en VILLALOBOS CALDERÓN, Liborio (comp.) La Convención Radical Obrera. La Antología, p.44.

32 La Convención Radical, 22 de mayo de 1887, en VILLALOBOS CALDERÓN, Liborio (comp.) La Convención Radical Obrera. La Antología, p.42.

33 Durante el porfiriato, esta contradicción -o tensión entre libertad y coacción- se hace evidente con la promulgación de diversas leyes y códigos que "se convirtieron en el instrumento mediante el cual el Estado buscó regular prácticamente todos los planos y los eventos de la vida social, incluso algunos del ámbito privado. [Los códigos legales] se ocuparon del perfil que debían presentar los mexicanos delineando muchas de las costumbres o de los hábitos que en su opinión debían adoptar. Asimismo, se encargaron de dictar los principios éticos o de velar por la moral de los individuos. SPECKMAN, Elisa. Las tablas de la ley en la era de la Modernidad. Normas y valores en la legislación porfiriana, en AGOSTONI, 
Retomando los aportes de Norbert Elías podemos decir que los mandatos sociales -en este caso los vinculados con la vestimenta-, al pautar lo correcto de lo que no lo es, configuran en los sujetos un aparato de costumbres, de autocontrol. "El individuo teme perder el aprecio o la consideración de otros cuyo aprecio y consideración le importa o le ha importado". ${ }^{34}$ Por lo tanto, el conocimiento de las posibles consecuencias de su conducta lo lleva a ejercer sobre sí mismo una regulación que termina conformando un proceso modelador de lo social ya que, finalmente, "las coacciones sociales externas van transformándose en coacciones internas". ${ }^{35}$ En síntesis, el entramado de las relaciones de interpersonales tejen un aparato social donde las coacciones que unos hombres ejercen sobre otros se convierten en autocoacciones. ${ }^{36} \mathrm{El}$ siguiente párrafo condensa este problema:

\begin{abstract}
El hombre asociado procura desde luego presentarse dignamente, anhela por su propia conveniencia que nada sea censurable en la conducta que observe y tiene como estímulos entre otros, para su adelanto, el ver que aquellos por su instrucción, buenos principios y honradez, son acreedores a las consideraciones públicas y que la corporación de la que forman parte los distingue aprovechando sus útiles servicios, confiriéndoles los cargos principales. Esto hace que los antes obreros rudos, sin ambición, sientan el deseo de hacerse dignos [... ] y voluntariamente se dedican a instruirse, logrando al fin y al cabo su objeto, y como la instrucción es la base de una buena moral, se moralizan, se avergüenzan de ser viciosos y se regeneran, transformándose en hombres útiles. ${ }^{37}$
\end{abstract}

Asimismo, en consonancia con los imperativos de las elites políticas, los líderes mutualistas remarcaron la importancia de la moderación y el ahorro entre los trabajadores como una premisa que colaboraría en la consolidación del mercado interno y la industria. En este sentido, la prensa obrera de fines del siglo XIX reflejó una preocupación central: la pronta consolidación de una sociedad de consumo necesitaba de obreros y artesanos conscientes de los beneficios del hábito del ahorro y la templanza, condiciones ineludibles para alejarlos de los derroches de la taberna, el juego y el alcoholismo y acercarlos, en calidad de consumidores, a la industria nacional. Un artículo aparecido en la prensa obrera estimaba que en la capital de la República

Claudia y Elisa SPECKMAN. Modernidad, tradición y alteridad. La ciudad de México en el cambio del siglo (XIX y XX), pp.243-244.

34 ELÍAS, Norbert. El proceso de la civilización. Investigaciones sociogenéticas y psicogenéticas. México: Fondo de Cultura Económica, 1994, p.500.

35 ELÍAS, Norbert. El proceso de la civilización. Investigaciones sociogenéticas y psicogenéticas, p. 449.

36 La misma subversión a las normas o convenciones muchas veces presenta un carácter ambiguo, dejando entrever las tensiones de la autocoacción con la resistencia. Un ejemplo ilustrativo lo constituyó la movilización popular que tuvo lugar el 17 de octubre de 1945 en la ciudad de Buenos Aires cuando varios de los manifestantes, en su mayoría obreros, se lavaban los pies en la fuente de Plaza de Mayo, apropiándose y desacralizando un espacio simbólico de la tradición política, pero vestían saco, respetando las normas que imponían su uso para ir al centro de la ciudad. PLOTKIN, Mariano. Mañana es San Perón. Propaganda, rituales políticos y educación en el régimen peronista (1946-1955). Buenos Aires: Ariel, 1994.

37 La Convención Radical Obrera, 15 de julio de 1888. 
mexicana alrededor de 8.000 obreros se hallaban completamente ajenos a toda "regla social"; ahora bien, si se lograba transformar sus perniciosas costumbres

darían doble vida a la industria y al comercio; es decir, ayudarían de una manera extraordinaria a esos dos elementos de la riqueza; y si ese cálculo que hemos hecho de la capital, lo hacemos extensivo a la República, resultaría que las actuales fábricas y los establecimientos de comercio hoy existentes, no darían la suficiente cantidad de productos que solamente la clase obrera necesita para sí. ${ }^{38}$

Otra arista de las estrategias coercitivas vinculadas al vestuario de las clases populares fueron las articuladas para uniformar el contingente laboral urbano. "A la organización oficial de los voceadores de periódicos siguieron los cocheros, luego los billeteros, después los cargadores, enseguida los aguadores y en fin los individuos de cada ramo tendrán un vestido especial que les distinga y sirva de contraseña en el oficio profesado". ${ }^{39}$ La disposición de uniformar a los vendedores ambulantes comenzó por los voceadores de periódico, reglamentación donde los prejuicios se entrecruzaban con la necesidad de organizar, regular y controlar el mundo del trabajo urbano. Estos papeleros, como también se los llamaba, eran en su mayoría niños y jóvenes que pasaban gran parte del día en la calle y, a decir de la prensa, "no sabían leer, usan un lenguaje tabernario, visten harapos sucios, no se lavan ni peinan el cabello [... ] pierden el amor al hogar y al trabajo [...] de lo que hemos deducido que son verdaderamente vagos con tendencia a ser nocivos, si es que no lo son ya". ${ }^{40}$

La voluntad de uniformar evidencia la necesidad de regular el trabajo de los voceadores, para cuyo fin, según la disposición gubernamental, se escogerían sólo cien voceadores a quienes el Ayuntamiento les proporcionaría el uniforme y la placa que permitiría su identificación y los distinguiría del resto de esos "pequeños bohemios, que son, sin poderlo negar, unos verdaderos vagos". ${ }^{41} \mathrm{El}$ uniforme y la patente pretendían convertirse en requisitos ineludibles para ejercer el "voceo de papeles", la ausencia de estos símbolos de la coacción implicaba la aprehensión del infractor, quien asimilado a la categoría de vago pasaba a la Escuela correccional o a realizar

38 La Paz Pública, reproducido en El Socialista, 18 de marzo de 1888, en FERNÁNDEZ, J orge. Recopilación hemerográfica. Revista Historia Obrera, ciudad de México, vol. V, n¹7, 1979, p.9. Gómez Galvarriato subraya que Fernando Rosenzweig fue uno de los primeros historiadores en señalar que "el principal freno al desarrollo industrial de México [durante el porfiriato] fue el limitado crecimiento del mercado interno, provocado por el lento progreso en el nivel de vida de las clases medias y bajas [... ] que eran sus principales consumidores". GÓMEZ GALVARRIATO, Aurora. Industrialización, empresas y trabajadores industriales, del porfiriato a la revolución: la nueva historiografía. Revista Historia Mexicana, ciudad de México, vol. LII, n³, p.777, enero-marzo de 2003.

39 Diario del Hogar, 15 de marzo de 1888. Este problema es abordado para la primera mitad del siglo XIX por PÉREZ TOLEDO, Sonia. Trabajadores urbanos, empleo y control en la ciudad de México en LIDA, Clara y Sonia PÉREZ TOELDO. Trabajo, ocio y coacción. Trabajadores urbanos en México y Guatemala en el siglo XIX. México: Universidad Autónoma Metropolitana, Miguel Ángel Porrúa, 2001, pp.157-198.

40 La Convención Radical, 23 de octubre de 1887.

41 La Convención Radical, 23 de octubre de 1887. 
trabajos en la Penitenciaría. ${ }^{42}$ Asimismo, la disposición se justificaba teniendo en cuenta que el uniforme colaboraría en la adquisición de hábitos de aseo que, como ya mencionamos, no fue menos importante en una ciudad que pretendía erigirse como símbolo del progreso. ${ }^{43}$

En este caso, la regulación del trabajo estaba impregnada de prejuicios, de una carga moral que levantaba sobre estos jóvenes la permanente sospecha de la trasgresión, el escándalo y la vagancia. La definición de voceador se movía entre límites imprecisos, fluctuaba entre la condición de vago y la propia de un trabajador urbano. Ahora bien, en la regulación de este oficio, la coacción asumía claras connotaciones de censura, el gobierno consideraba que los papeleros alarmaban a "la población con noticias falsas o adulteradas" y, lo que podía ser peor, daban publicidad de actos delictivos y conductas sociales reprobatorias ${ }^{44} \mathrm{EI}$ contrapunto de esta medida fue denunciado por los periódicos independientes de la capital, los cuales señalaban que sus noticias no eran voceadas porque "nadie se atreve a anunciarlas ni siquiera en voz baja" por temor a las acciones represivas del gobierno ${ }^{45}$. De esta manera, el uniforme se convertía en el símbolo de la vigilancia, de la coacción y del control del trabajo ejercido sobre los sectores populares; era la marca visual que distinguía a los vagos de los laboriosos y era el estigma de la censura del régimen sobre la prensa independiente y la libre circulación de información ${ }^{46}$.

En este mismo sentido, otro ejemplo de las medidas tendientes a consolidar apariencias acordes a la anhelada modernidad lo constituyó la reglamentación del uso del pantalón. Esta prescripción, promovida en 1887 por el gobernador del Distrito Federal, nació estrechamente vinculada con el mundo del trabajo. "El Gobierno ha prevenido que en el término de ocho días usen pantalón todos aquellos individuos a quienes se les inscriba en la sección respectiva de la Secretaría para el ejercicio de diversas industrias, como los vendedores ambulantes de billetes y periódicos, aguadores, car-

42 Diario del Hogar, 21 de enero de 1888. Sonia Pérez Toledo señala, para la primera mitad del siglo XIX, que los vagos "estuvieron sujetos a una legislación que castigaba el ocio y la mendicidad. En la ciudad de México, eran juzgados en el tribunal de vagos desde su creación en 1828 y -si nos atenemos sólo a la legislación- tenían como destino la cárcel, las obras públicas, las armas o el exilio, así como el aprendizaje de un oficio en el Hospicio de Pobres o en un taller público, cuando se trataba de menores de edad". PÉREZ TOLEDO, Sonia. Trabajadores urbanos, empleo y control en la ciudad de México en LIDA, Clara y Sonia PÉREZTOELDO. Trabajo, ocio y coacción. Trabajadores urbanos en México y Guatemala en el siglo XIX, pp.180-181.

43 El Siglo Diez y Nueve, 5 de marzo de 1888. En 1901 la falta de higiene personal de los vendedores ambulantes "inspiraba repugnancia" en los transeúntes. En tal sentido, las señoras evitaban que sus hijos compren golosinas a "los vendedores desaseados [circunstancia que condujo a un grupo] de damas acomodadas a proporcionarles los medios de que se presenten aseados, lo que indudablemente aumentará su clientela. Les suministrarán lo necesario para que laven sus ropas". El Imparcial, 27 de diciembre de 1901, en DE GORTARI RABIELA, Hira y Regina HERNÁNDEZ FRANYUTI (coords.) Memoria y encuentros: La ciudad de México y el Distrito Federal (18241928). México: Departamento del Distrito Federal, Instituto de Investigaciones Dr. J osé María Luis Mora, 1988, t. III, p.207.

44 La Convención Radical, 23 de octubre de 1887.

45 Diario del Hogar, 3 de marzo de 1888.

46 Un análisis de los mecanismos y estrategias de censura del gobierno de Porfrio Díaz sobre la prensa independiente, en GANTÚS, Fausta. Caricatura y poder político. Crítica, censura y represión en la ciudad de México, 1876-1888. México: El Colegio de México, 2007 (Historia, tesis de doctorado). 
gadores, etc.". ${ }^{47}$ Ahora bien, si retomamos algunas coyunturas en el derrotero de la preocupación gubernamental por desterrar el uso del calzón de manta, podemos decir que esta empresa estuvo signada por una recurrente resistencia de los sectores populares a vestir pantalones.

Tres años después, en 1890, el municipio de la ciudad de México aprobó nuevamente una medida que pretendía generalizar el uso del pantalón entre los trabajadores del Ayuntamiento. La disposición iría dirigida, en un primer momento, a uniformar a aquellos trabajadores ocupados en la manutención y construcción de obras públicas urbanas, así como a la multitud de operarios que laboraban en las comisiones municipales, como la de Limpia o la de Paseos. El Ayuntamiento, a fin de hacer extensiva al conjunto de las clases trabajadoras capitalinas esta reglamentación, buscaría la alianza con los dueños de fábricas y talleres, así como con ingenieros, arquitectos e industriales, quienes -en estrecha colaboración con las autoridades políticas- obligarían a sus trabajadores a vestir pantalón, generalizando así su uso.

Según las autoridades capitalinas, la obligatoriedad del uso de esa prenda de vestir contrarrestaría la "desagradable impresión que recibe el extranjero cuando al llegar a nuestra ciudad observa el estado que guarda la parte más pobre de sus habitantes y señaladamente el traje con que éstos se cubren". Esta vez los prejuicios de las elites porfirianas aparecían disfrazados tras la supuesta mirada del visitante extranjero; ahora bien, más allá de los disimulos era claro que para ciertos sectores de la población capitalina, la falta de pantalón hacía que "la vista de la clase social a que antes nos referimos sea desagradable y en no pocos casos impúdica". A decir de los promotores del proyecto, la conjunción de esfuerzos destinados a imponer el uso del pantalón entre las clases trabajadores, promovidos por la complementariedad de intereses públicos y privados, redundaría en bien de la "cultura social [...] y hasta en bien de la moral". ${ }^{48}$

Ahora bien, a pesar de las reglamentaciones y disposiciones, a principios del siglo XX el uso del calzón de manta por los sectores populares seguía siendo un estigma en los proyectos modernizadores y el cosmopolitismo propugnado por las autoridades políticas. En 1904, Arturo Ruiz, alumno de la Escuela de Medicina, retomaba en su tesis esta preocupación y anhelaba que "en nombre de la Higiene y de la Moral [...] se declare obligatorio el uso del pantalón. Hay en esto una cuestión moral que interesa a la sociedad, y una cuestión higiénica que incumbe al individuo". ${ }^{49} \mathrm{Al}$ parecer, más allá de los bandos, las disposiciones y la obligatoriedad con que las autoridades intentaron generalizar el uso del pantalón, la negativa

47 El Hijo del Ahuizote, 3 de julio de 1887.

48 Archivo Histórico del Distrito Federal, Fondo Policía General, vol. 3638, exp. 975.

49 RUIZ, Arturo. El vestido ante la higiene, p. 26. 
de las clases populares a "forrarse las piernas, y ceñirse la cintura"50 revela la persistencia de una costumbre que intentó resistir los embates coactivos y modernizadores porfirianos.

\section{Consideraciones finales}

Para las elites porfirinas de fines del siglo XIX, la ausencia de hábitos de higiene personal y la persistencia de ciertas prendas de vestir, asociadas con la tradición indígena, contrariaban la anhelada consolidación de la ciudad de México como símbolo de la modernidad y el progreso nacional. En esta tónica de preocupaciones, un supuesto que se impuso cada vez con mayor insistencia fue el que sostenía que el uso de calzones de manta y huaraches, así como una piel carente de aseo, revelaban la existencia de un cuerpo donde el delito se encontraba latente. La falta de moral de un individuo quedaba expuesta a la vista de la sociedad a través de su apariencia, a partir de ésta era posible juzgar conciencias y predecir comportamientos. En esta cadena de causalidades y prejuicios: el alcoholismo, el ausentismo laboral -encarnado en el San Lunes- y la delincuencia eran conductas previsibles entre quienes carecían de costumbres higiénicas 0 insistían en el uso de ciertos atuendos. Por tanto, a través de la apariencia era posible identificar a los potenciales conspiradores del orden social y la paz porfiriana.

En este contexto, las elites políticas diseñaron una serie de medidas coercitivas destinadas a inculcar hábitos de higiene personal; modificar el atuendo de los trabajadores ambulantes, mediante la obligatoriedad del uso del pantalón; y transformar la forma de vestir de los indígenas, particularmente desterrar ciertas prendas tradicionales como el calzón, el sarape y los huaraches. Paradójicamente, a lo largo del siglo XIX a la vez que el discurso liberal hacía hincapié en la igualdad jurídica y los derechos individuales, desterrando los vínculos y privilegios de carácter corporativo, articulaba mecanismos coactivos destinados a cercenar y restringir costumbres y conductas del ámbito privado. En síntesis, "vemos que, por una parte, se formulaban los derechos y las libertades individuales, incluyendo la libertad de trabajo [...] a la vez que, por la otra, se creaban los instrumentos que coartaban aquellas actividades individuales y colectivas que se percibieran como contrarias al orden y los valores de quienes dominaban la esfera pública". ${ }^{51}$

Sin embargo, como lo señaló Edward P. Thomspon, la dialéctica entre los imperativos de la dominación y la resistencia a esa imposición ha sido

50 El Hijo del Ahuizote, 10 de julio de 1887.

51 LIDA, Clara y Sonia PÉREZ TOELDO. Trabajo, ocio y coacción. Trabajadores urbanos en México y Guatemala en el siglo XIX, p.6. 
central en el desarrollo histórico52. Por tanto, los mecanismos coactivos para controlar y moldear las conductas de los sectores populares y regular aquellas prácticas y comportamientos que consideraban atentatorios del orden y la modernidad debieron superar costumbres seculares, prejuicios populares y limitantes económicas de "los de abajo". Estos tópicos conformaron una compleja urdimbre, un filtro que actuó como mediador y condicionante de las deseables y modernas conductas sociales, involucrando a un numeroso segmento de la población capitalina en un juego de coacciones, resistencias y negociaciones.

52 THOMSPON, Edward. Las peculiaridades de lo inglés y otros ensayos. Valencia: Centro Francisco Tomás y Valiente UNED Alzira-Valencia, Fundación Instituto de Historia Social, 2002, p.113. 